\title{
Downstream Effects on Orbiter Leeside Flow Separation for Hypersonic Flows
}

\author{
Gregory M. Buck ${ }^{*}$ and Maria V. Pulsonetti, \\ NASA Langley Research Center, Hampton, Virginia \\ K. James Weilmuenster ${ }^{\dagger}$ \\ North Carolina State University, Raleigh, North Carolina
}

\begin{abstract}
Discrepancies between experiment and computation for shuttle leeside flow separation, which came to light in the Columbia accident investigation, are resolved. Tests were run in the Langley Research Center 20-Inch Hypersonic $\mathrm{CF}_{4}$ Tunnel with a baseline orbiter model and two extended trailing edge models. The extended trailing edges altered the wing leeside separation lines, moving the lines toward the fuselage, proving that wing trailing edge modeling does affect the orbiter leeside flow. Computations were then made with a wake grid. These calculations more closely matched baseline experiments. Thus, the present findings demonstrate that it is imperative to include the wake flow domain in CFD calculations in order to accurately predict leeside flow separation for hypersonic vehicles at high angles of attack.
\end{abstract}

\section{Nomenclature}

$\mathrm{CF}_{4} \quad=$ fluoromethane (test gas used in the Langley Research Center 20-Inch Hypersonic $\mathrm{CF}_{4}$ Tunnel)

$\operatorname{Re}_{L} \quad=$ freestream Reynolds number based on vehicle length

$R C C=$ Reinforced Carbon-Carbon

\section{Introduction}

$\mathrm{T}_{\mathrm{c}}^{\mathrm{H}}$ HE leeside flow field for the shuttle orbiter was examined both experimentally and computationally ${ }^{1,2}$ for the Columbia accident investigation to aid in the analysis of anomalous temperature readings recorded on the leeside fuselage. Figs. 1, 2, and 3 show results from wind-tunnel experiments, illustrating the leeside flow field for the orbiter. Figure 1 shows comparisons of experimental heating and streamline patterns; Fig. 2 shows postulated leeside flow fields; and Fig. 3 shows the overall effect of a missing RCC wing leading edge panel as inferred from these wind-tunnel measurements. While most of the computations were run at flight conditions for the accident investigation, some cases were run solely to interpret these hypersonic wind-tunnel data. Although both the experimental and computational data were then shown to support the anomalous flight temperature readings on the side of the fuselage prior to loss of Columbia, based on a missing wing leading edge panel, ${ }^{1,2}$ there remained significant differences between experiment and numerical simulations associated with leeside flow separation on the wing surface, affecting a significant area of the wing surface. A comparison of the separation lines between experiment and initial computation are shown in Fig. 6. Whereas the computed separation lines continue downstream from the wing strake fairly close to the fuselage, in experiments the separation lines flare out considerably, more nearly parallel to the wing leading edge.

To the authors' knowledge, no comprehensive, systematic comparison has been made for orbiter leeside flowfield/surface predictions between computational and experimental techniques. Computations have been made to compare with sparse flight pressure measurements and infrared thermal images on the leeside surface of the orbiter $^{3}$. When computing leeside surface values, computations matched flight pressure data only on the wing surface near the leading edge but deviated significantly at mid-chord and downstream on the leeside wing surface.

\footnotetext{
* Aerospace Technologist, Aerothermodynamics Branch, Mail Stop 408A, Hampton VA, 23681.

${ }^{\dagger}$ Visiting Researcher, Mail Stop 408A, Hampton VA, 23681.
} 
The discrepancies downstream were originally thought to be a result of gaps between the orbiter aileron surfaces not matched in the computational grid; however, the issues were left mainly unresolved.

\section{Initial Computations}

Initial computations were performed at wind tunnel conditions, simulating the wind tunnel experiments of scaled Orbiter models in the NASA Langley 20-Inch Hypersonic $\mathrm{CF}_{4}$ Tunnel. The computational grid had 8 million grid points and was adapted to align the grid with the bow shock about the Orbiter model. The grid was truncated at the wing trailing edge of the model. The grid had 304 cells streamwise, 400 cells spanwise wrapping around the wing, and 64 cells normal to the body. Details of the surface and volume grids are shown in Figs. 4 and 5.

The computations were performed using the Langley Aerothermodynamic Upwind Relaxation Algorithm (LAURA) code. ${ }^{6,7}$ LAURA is a computational fluid dynamics (CFD) tool specialized for hypersonic re-entry physics and chemistry. The initial wind tunnel computations were performed assuming a laminar boundary layer. Perfect gas conditions for $\mathrm{CF}_{4}$ were assumed due to the extremely low temperatures of the flowfield. The wall was assumed to be at a constant temperature of $300 \mathrm{~K}$. Initial calculations were performed using the thin-layer formulations of the Navier-Stokes equations.

Figure 6 shows the comparison of the initial computations and the experiment leeside surface streamlines for a given test $\left(0.004\right.$ scale Orbiter, $\left.\operatorname{Re}_{\mathrm{L}}=324,000\right)$. A major discrepancy existed between the experiment and computations in that the leeside flow separation on the wing immediately downstream from the leading edge did not match, effecting a significant area of the wing surface.

\section{Initial Experiments}

Wind-tunnel experiments were run in three different hypersonic blow-down facilities at NASA Langley Research Center using a new in-situ fluorescent oil flow technique that distinctly shows the flow separation lines on the wind-tunnel model during the run. This technique uses a fluorescent powder, which is sprinkled on a coating of clear oil applied to the test model surface before each run. During the run the fluorescent powder is excited using an ultraviolet bandpass filtered mercury arc lamp (365 nanometers wavelength) and the emitted visible light pattern is recorded using a digital video camera. Flow separation lines are particularly highlighted as the fluorescent powder is collected via converging surface streamlines and the emitted brightness is a function of the powder density.

These tests were run in the 20-Inch Hypersonic $\mathrm{CF}_{4}$ Tunnel, 20-Inch Mach 6 Air Tunnel, and 31-Inch Mach 10 Air Tunnel. A complete description of these facilities is given by Micol. ${ }^{4}$ A typical setup is shown in Fig. 7 for fluorescent oil flow measurements in the Langley 20-Inch Hypersonic $\mathrm{CF}_{4}$ Tunnel with a stainless steel 0.004 scale orbiter model. Both 0.004 and 0.0075 scale models were tested in both center sting mounted and tail blade mounted configurations to see if any tunnel or sting interference effects were present. All of the results, some of which are shown in Figs. 8, 9 and 10 were similar in that flow separation is indicated to occur near the wing leading edge at high Reynolds number, to move inward towards the fuselage at lower Reynolds numbers, and is always flared out somewhat parallel to the wing leading edge. This is also in agreement with earlier oil flow experiments. ${ }^{5}$ In this way, it has been determined that this is indeed a general experimental phenomena and not a result of testing in any particular facility, or a result of any particular test or support configuration. Wing leeside separation lines from insitu fluorescent oil flow images for the 0.004 scale orbiter in the hypersonic $\mathrm{CF}_{4}$ wind tunnel at $40^{\circ}$ angle of attack are shown in Fig. 11 for various length freestream Reynolds numbers.

\section{Further Computations}

The computations for the present report were performed for a 0.0075 scaled Orbiter model at two different Reynolds numbers $\left(\operatorname{Re}_{\mathrm{L}}=25,000\right.$ and 324,000). Further computations included turbulent boundary layer modeling and full Navier-Stokes formulation of the governing equations to test the influence of both on leeside flow separation. Otherwise, computations were performed in the manner mentioned in section II. Comparisons of the computed separation lines on the leeside wing are shown in Fig. 12. Turning on the turbulent option did not alter the computed separation line. This result was significant since there were some who expected that flow turbulence would have more of an effect on leeside flow separation. Not using the thin-layer approximation shifted the computed separation line outboard, but not close to the measured separation line. 


\section{Experimental Testing of Extended Wing Models}

It was hypothesized that the discrepancies observed between experiment and computation were a result of terminating the computational grid at the wing trailing edge, not allowing for windward flow effects to wrap around the vehicle from the windward to the leeward surface.

The effect of grid termination at the end of the vehicle is similar to modeling a vehicle with an infinite trailing edge, in that the pressure is not communicated from the windward to the leeward surface. To partially simulate these effects in the wind tunnel, models with extended trailing edges were tested. Figures 13 and 14 show the 0.004 scale orbiter models that were fabricated from a rapid prototype photo-setting resin material and coated with graphite. These models were fabricated with $15 \%(+1$ inch) and $30 \%(+2$ inch) extended bodies, beginning at the trailing edge for the leeside interface and maximum chord thickness for the windward interface.

At higher Reynolds number (Fig. 15) the 15 to 30 percent extensions did not have a large effect on the leeside flow separation, although at lower Reynolds number (Fig. 16), the effect was shown to be significant. It would be expected that a wing extension would have more of an effect when there is a lower pressure difference across the trailing edge. Figure 17 shows a comparison of the experiment results with the computations shown in Fig. 12. (Note that repeat runs for 2-inch extensions are shown for the lower Reynolds number case. A 1-inch extension was not run at this condition.) These data show that flow around the wing trailing edge has a significant effect on flow separation.

\section{Computations with an Extended Wake Grid}

In an attempt to more accurately match the experiment location of the wing leeside separation line, a computation was performed which included the simulation of the wake region behind the vehicle. For this computation a volume grid behind the vehicle was added to the existing grid. This new grid is shown in Fig. 18. For this grid 96 cells were added in the wake region in the streamwise direction. These computations were run laminar using a full Navier Stokes formulation of the governing equations. The presence of the wake in the computations had a significant effect on the leeside flow separation, as shown in Figs. 19 and 20. For the higher freestream Reynolds number, Fig. 19, calculations with the extended wake grid show separation lines significantly closer to experiment. Computations were run with full grid resolution and half resolution in the streamwise direction to test grid convergence. Surface streamlines were plotted in Fig. 19 for the case of lower grid resolution. The separation line for the full grid resolution in the streamwise direction tends further toward the experimental result, though not significantly, suggesting that possibly more is needed to accurately match the experiment than further grid refinement. Wake flow computations, however, closely match the experimental flow pattern characteristics, including the turning of the separation line, termination and distance from the trailing edge. Results shown in Fig. 20 for the lower Reynolds number case, though not matching the experimental characteristics, are closer in comparison than computations without the wake flow grid.

\section{Conclusion}

It has been shown both experimentally and computationally that downstream flow conditions for an orbiter-like configuration at high angle of attack in hypersonic flow have significant effects on leeside wing flow separation; that computations with downstream wake calculations more closely match experimental leeside surface characteristics; and, that inclusion of a downstream wake grid is critical for accurate prediction of leeside flow separation for hypersonic vehicles at high angles of attack.

\section{Acknowledgments}

G. M. Buck thanks Charles G. Miller for his physical insights into trailing edge effects on flow separation and Thomas J. Horvath for making this study fiscally possible.

\section{References}

${ }^{1}$ Horvath, T. J., "Experimental Aerothermodynamics in Support of the Columbia Accident Investigation," AIAA-2004-1387, AIAA 42nd Aerospace Sciences Meeting, Reno, 2004. 
${ }^{2}$ Pulsonetti, M. V. and Thompson, R. A., "LAURA Aerothermodynamic Computations for Space Shuttle Columbia STS-107 Baseline and Damage Scenarios," AIAA-2004-2278, AIAA 37th Thermophysics Conference, Portland, 2004.

${ }^{3}$ Kleb, W. L. and Weilmuenster, K. J., "Characteristics of the Shuttle Orbiter Leeside Flow During a Reentry Condition," AIAA-92-2951, AIAA 27th Thermophysics Conference, Nashville, 1992.

${ }^{4}$ Micol, J. R., "Hypersonic Aerodynamic/Aerothermodynamic Testing Capabilities at Langley Research Center: Aerothemodynamic Facilities Complex.: AIAA Paper 95-2107, 1995.

${ }^{5}$ Baranowski, L. C. and Kipp, H. W.. "A Study of Leeside Flow Field Heat Transfer on Shuttle Orbiter Configurations," NASA Contractor Report NAS1-16839, 1983.

${ }^{6}$ Gnoffo, P. A., Gupta, R. N., and Shinn, J., "Conservation Equations and Physical Models for Hypersonic Air Flows in Thermal and Chemical Nonequilibrium," NASA TP 2867, 1989.

${ }^{7}$ Gnoffo, P. A., "An Upwind-Biased, Point-Implicit Relaxation Algorithm for Viscous, Compressible Perfect-Gas Flows," NASA TP 2953, 1990. 

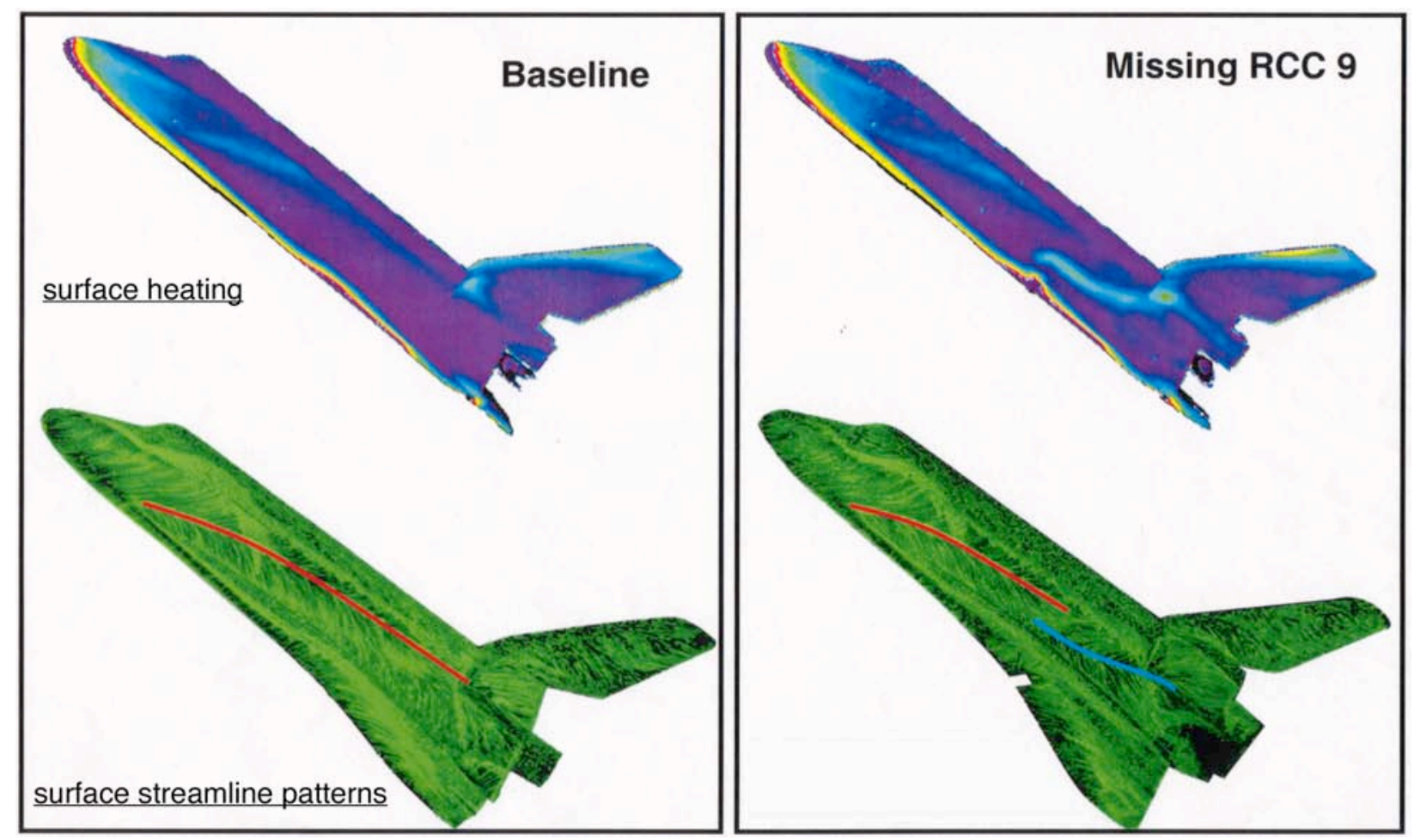

Figure 1. Comparison of heating and streamline patterns associated with damaged orbiter wing leading edge from hypersonic $\mathrm{CF}_{4}$ wind tunnel.

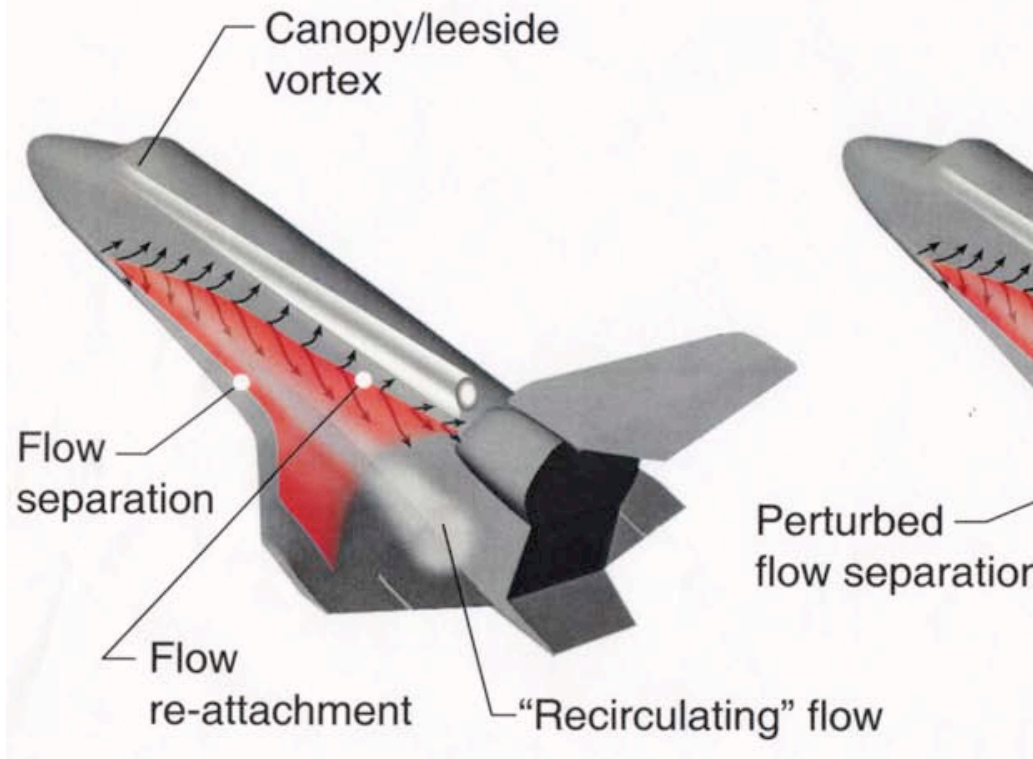

Baseline
Damaged leading edge

Figure 2. Postulated orbiter leeside flowfield associated with wing leading edge damage. (Wing leading edge damage perturbs leeward flow separation and re-attachment locations as well as leeward embedded shocks $\{$ not shown\}.) 


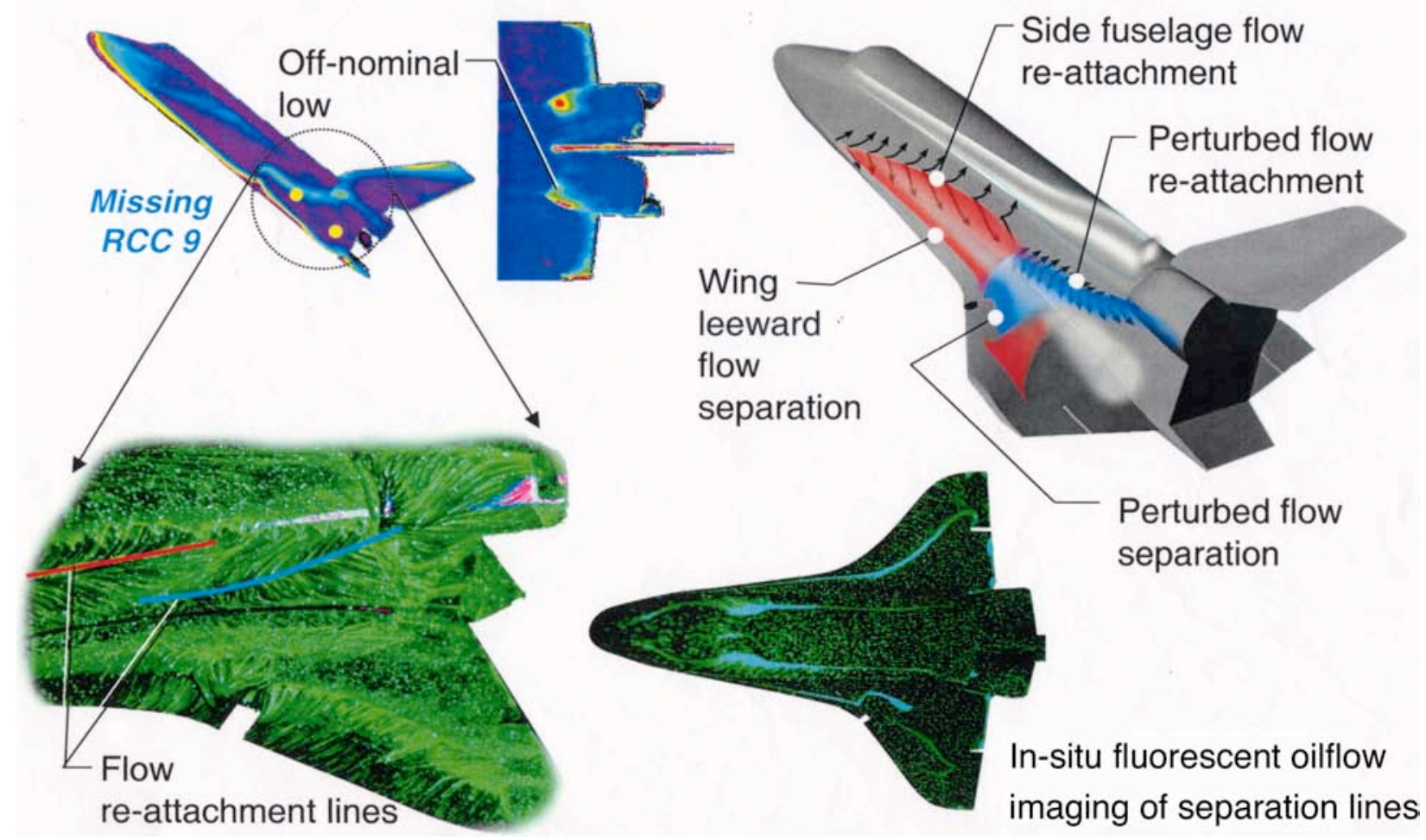

Figure 3. Effect of missing wing leading edge panel on orbiter leeside flowfield as inferred from surface heating and streamline patterns from hypersonic $\mathrm{CF}_{4}$ wind tunnel.
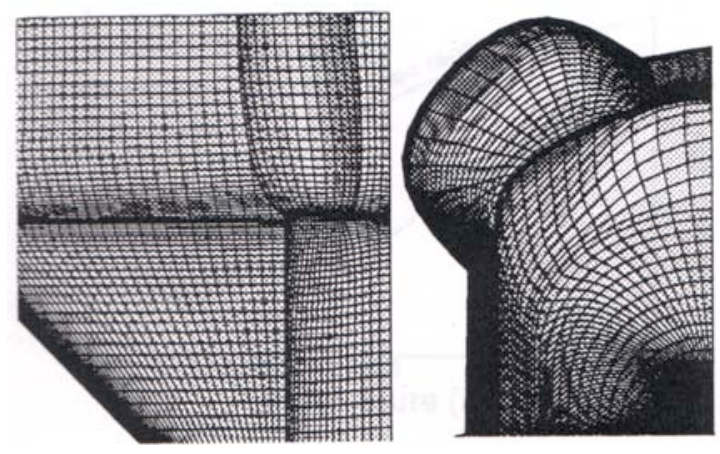

Figure 4. Planform and frontal details of the surface mesh.

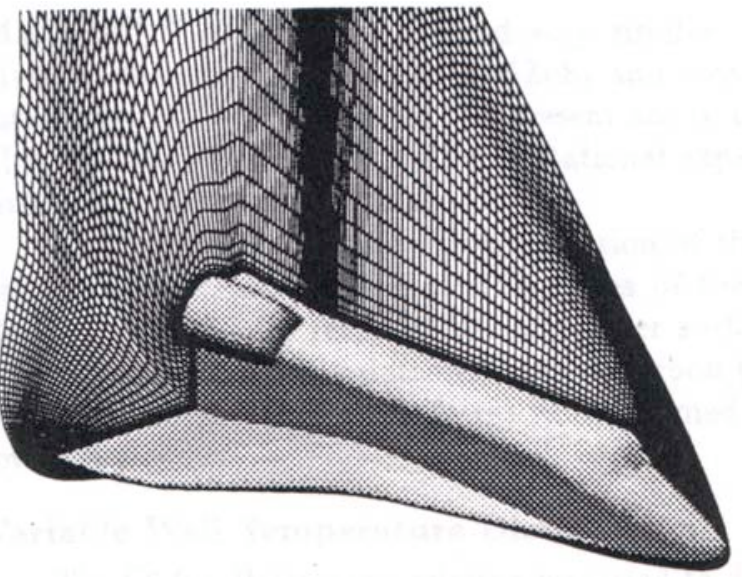

Figure 5. Partial view of volume grid (every other line perpendicular to the body-normal direction omitted for clarity). 


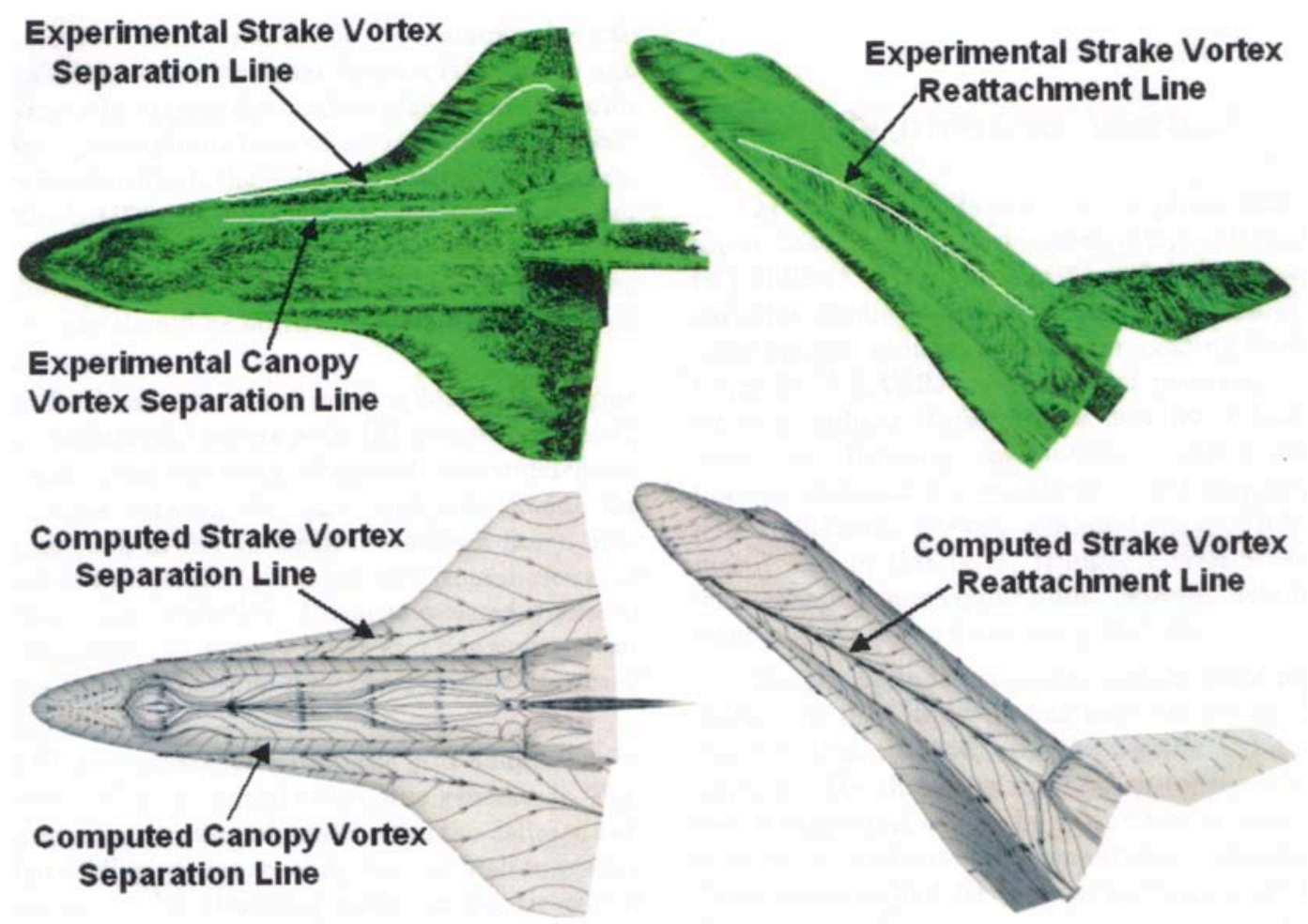

Figure 6. Comparisons of computed and experimental leeside surface streamlines for the baseline orbiter in hypersonic $\mathrm{CF}_{4}$.

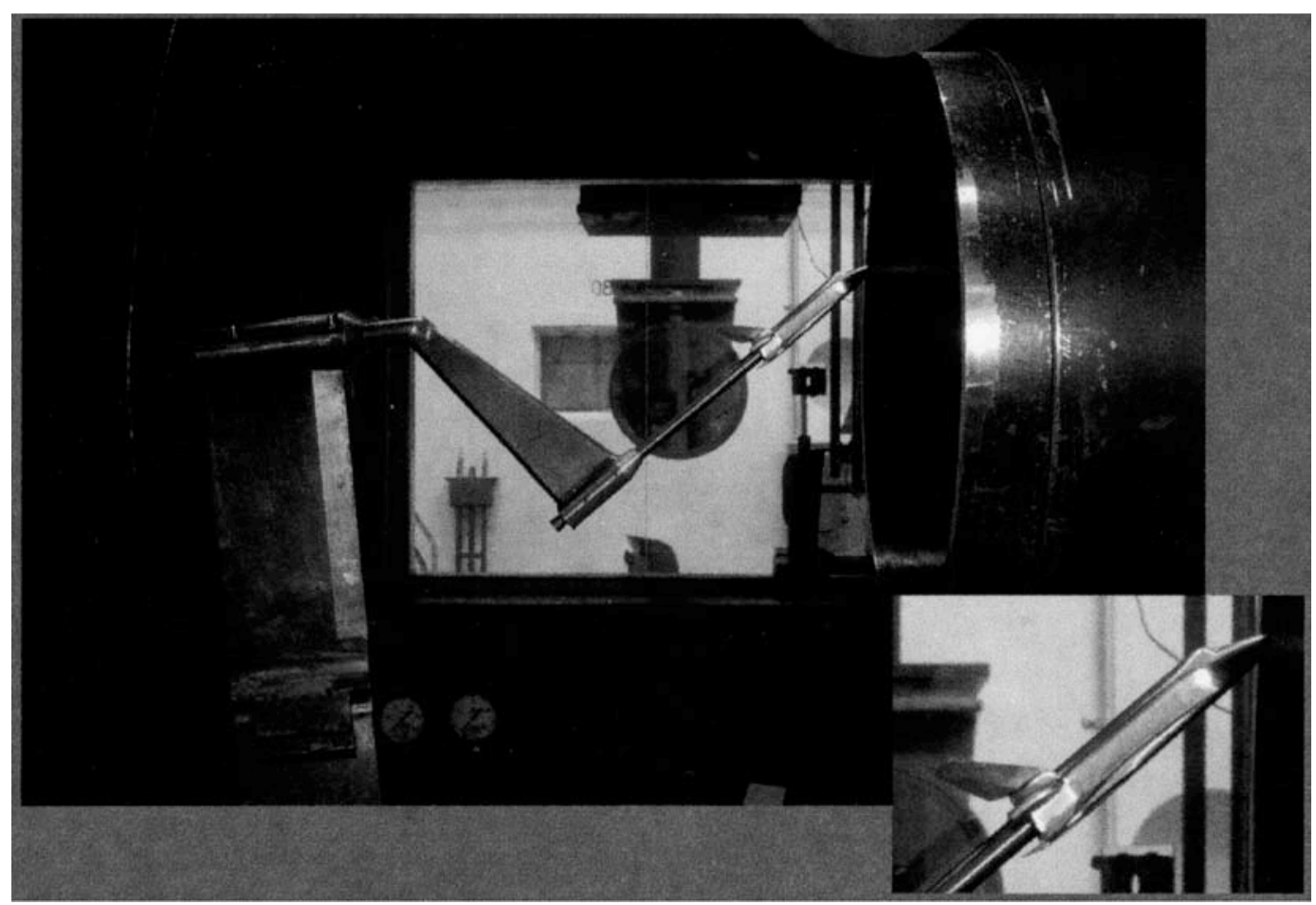

Figure 7. Orbiter model setup in hypersonic $\mathbf{C F}_{4}$ wind tunnel for fluorescent oil flow measurements. 

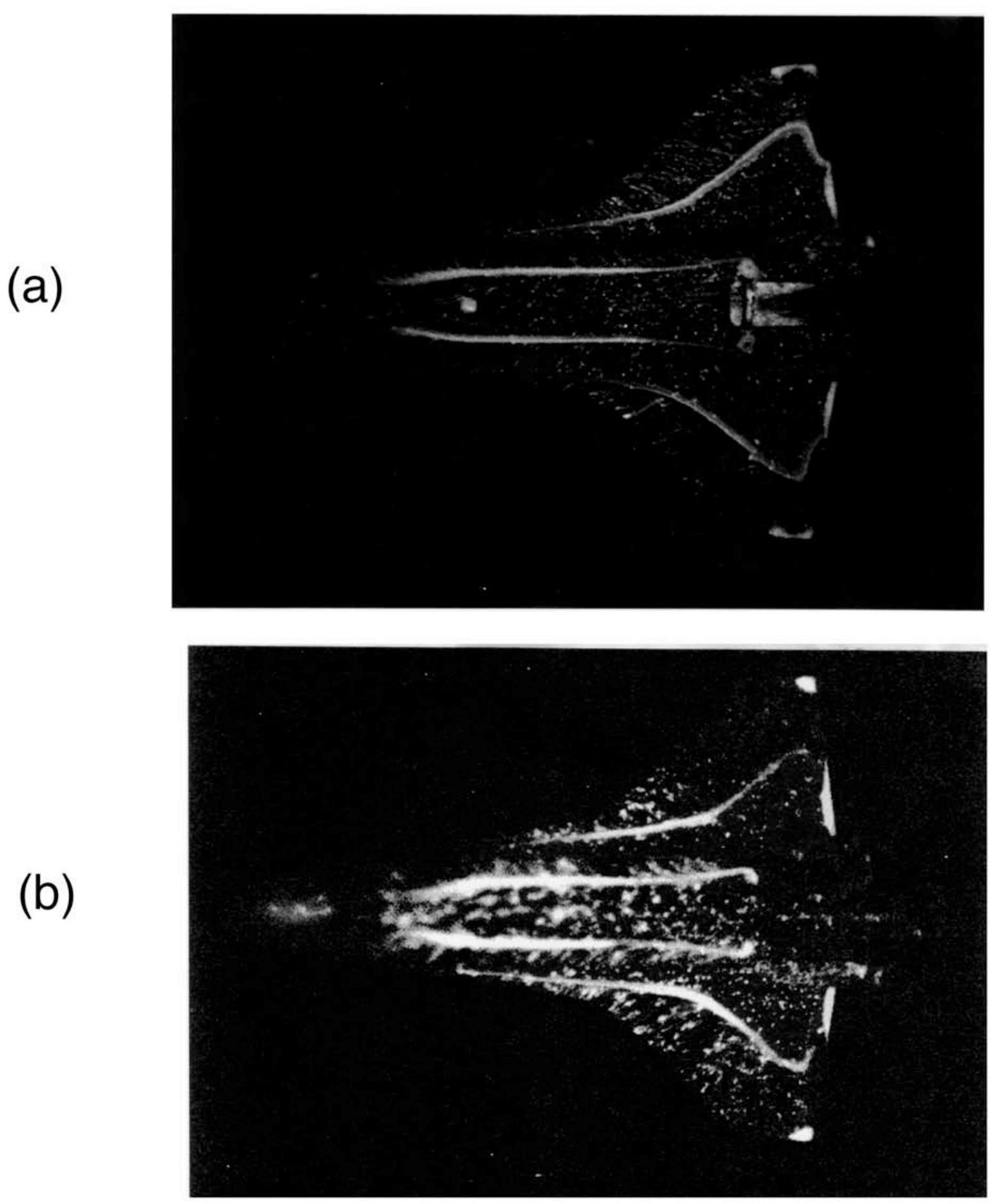

Figure 8. Separation lines from in-situ fluorescent oil flow on 0.004 scale orbiter in the hypersonic $\mathrm{CF}_{4}$ wind tunnel for (a) $\operatorname{Re}_{\mathrm{L}}=96,000$ and (b) $\mathrm{Re}_{\mathrm{L}}=43,000$. 
(a)

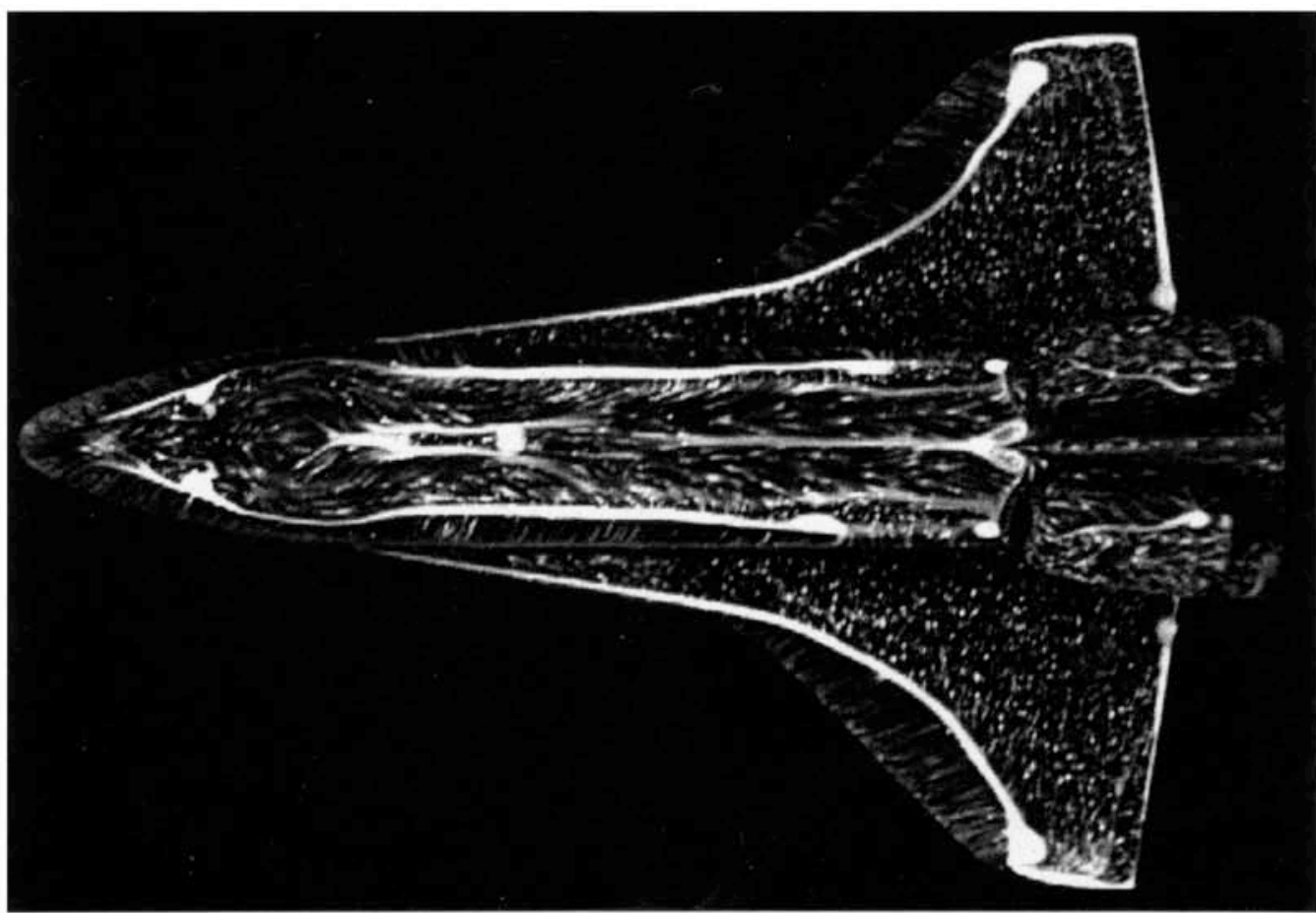

(b)

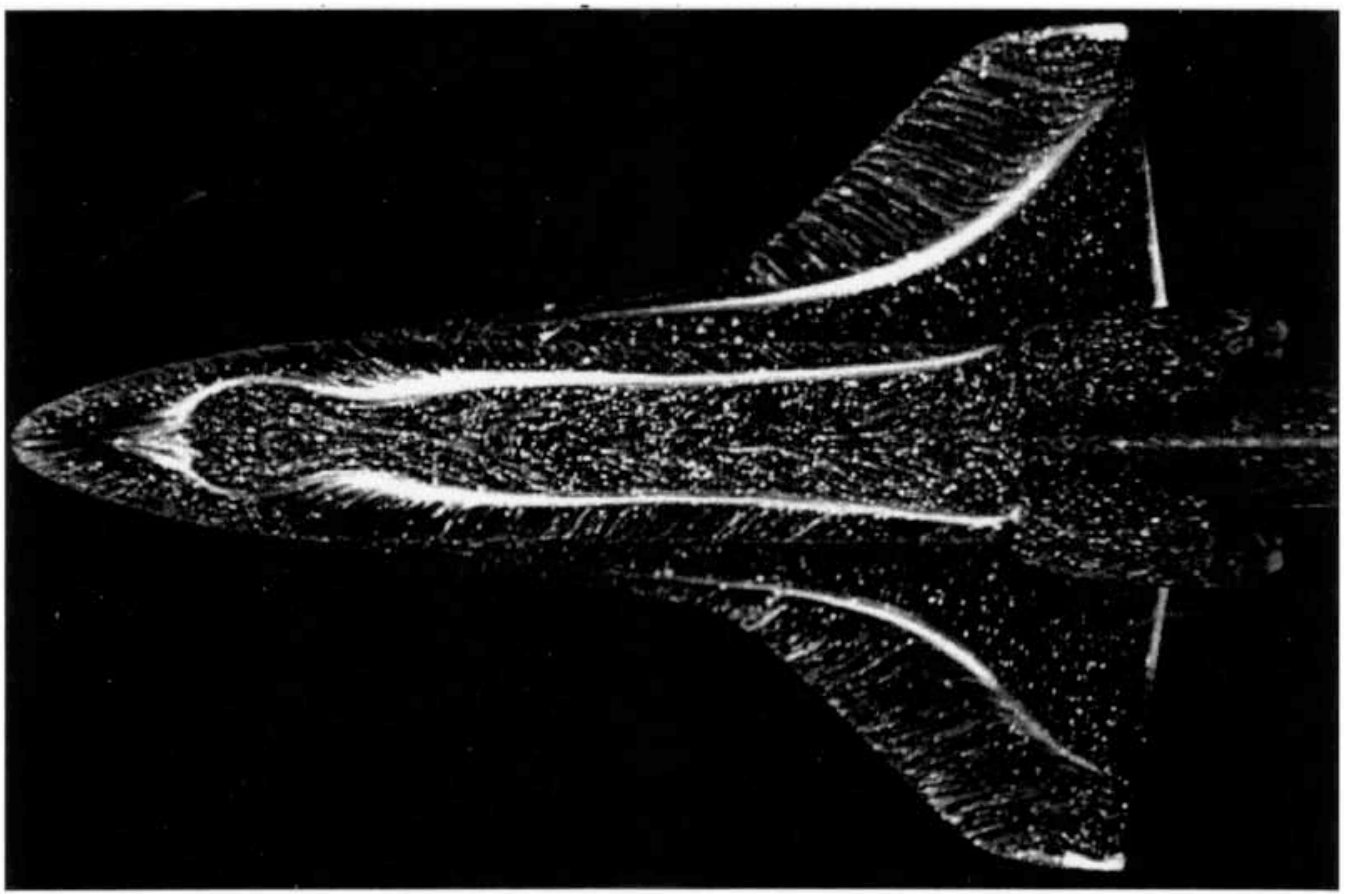

Figure 9. Separation lines from in-situ fluorescent oil flow on 0.004 scale orbiter in the Mach 6 Air wind tunnel for (a) $\mathrm{Re}_{\mathrm{L}}=1,750,000$ and (b) $\mathrm{Re}_{\mathrm{L}}=120,000$. 

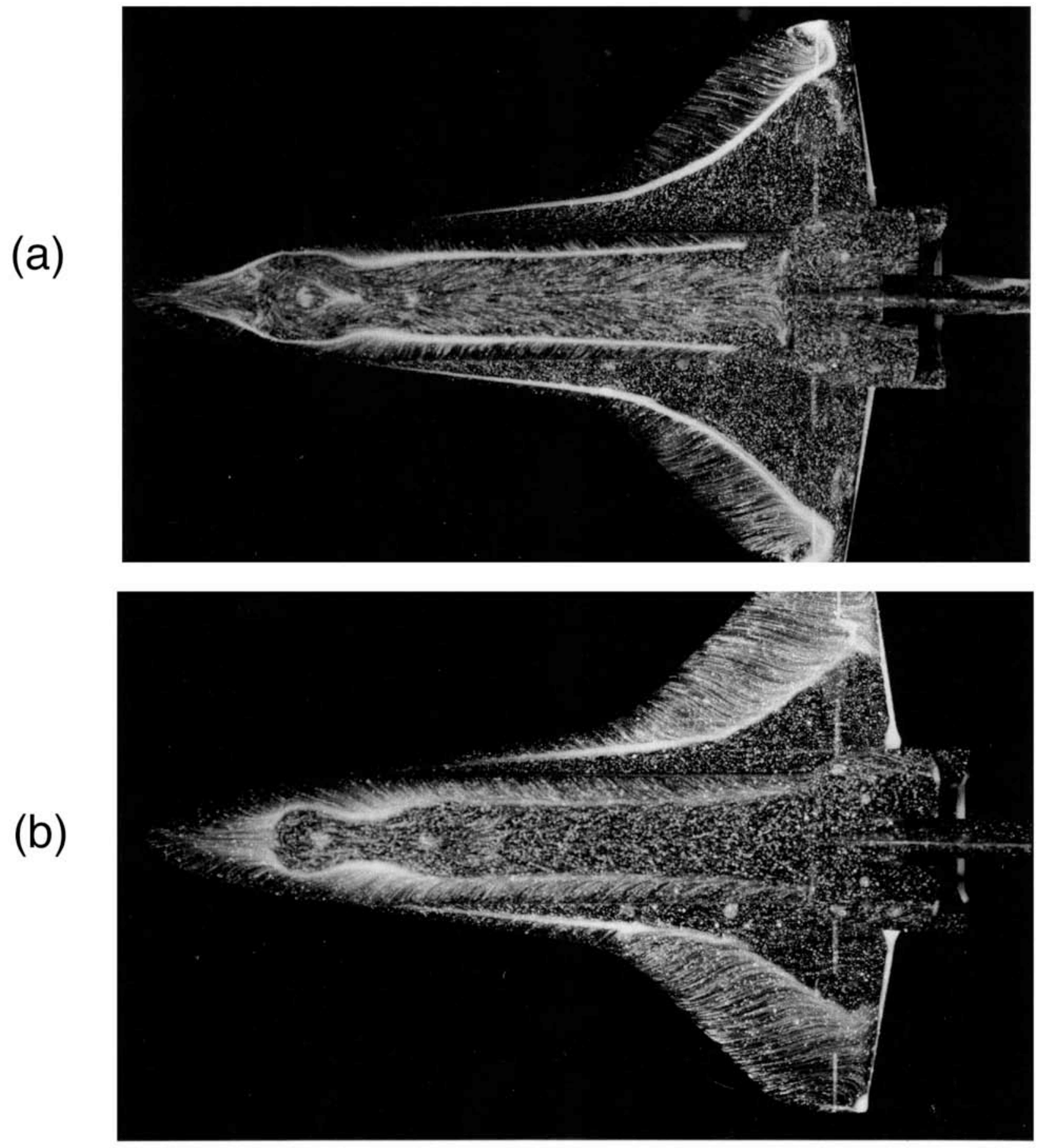

Figure 10. Separation lines from in-situ fluorescent oil flow on 0.0075 scale orbiter in the Mach 10 Air wind tunnel for (a) $R_{L}=840,000$ and (b) $R_{L}=150,000$. 


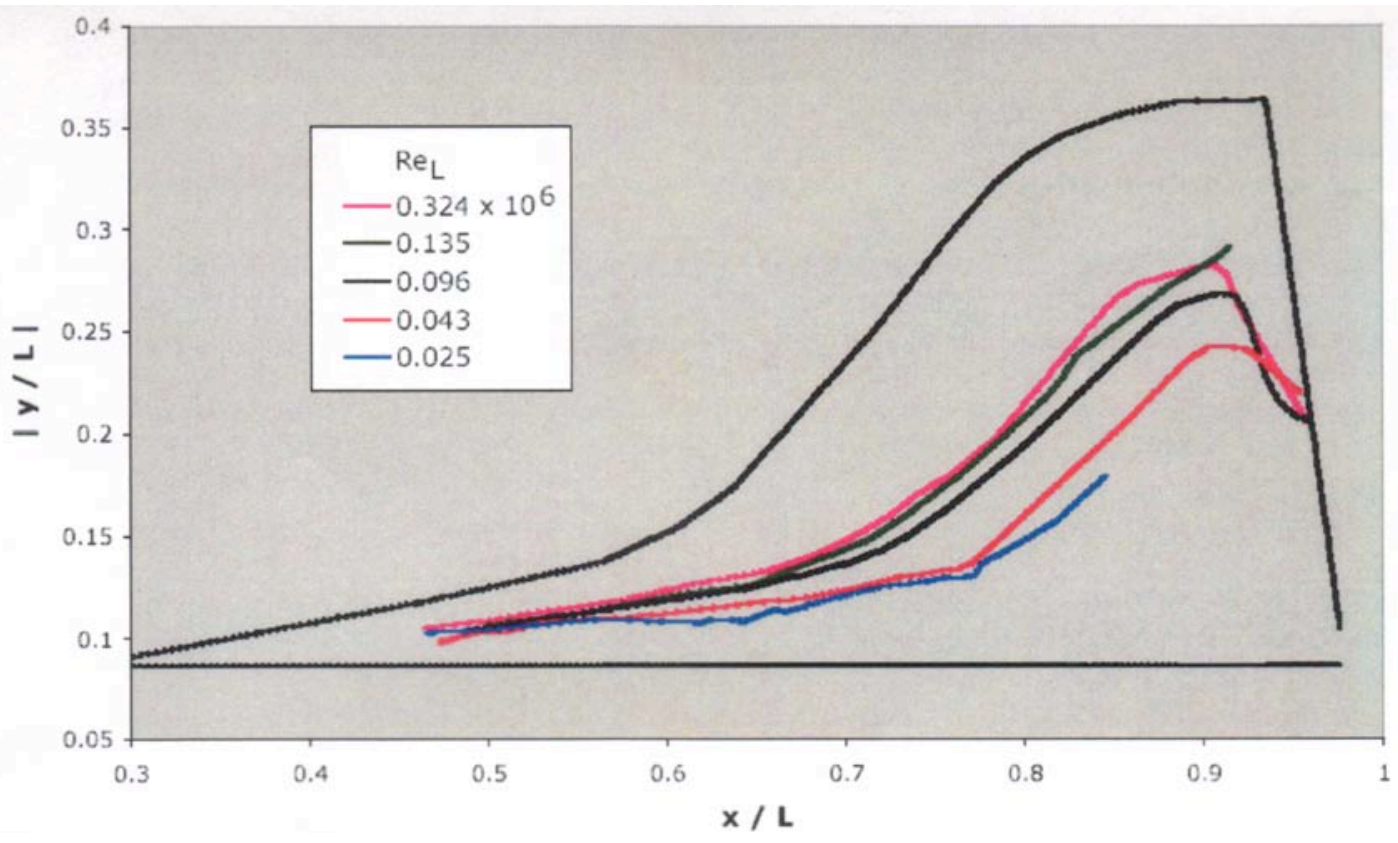

Figure 11. Wing leeside separation lines from in-situ fluorescent oil flow images for 0.004 scale orbiter in hypersonic $\mathrm{CF}_{4}$ wind tunnel at $\mathbf{4 0}^{\circ}$ angle of attack for various freestream Reynolds numbers.

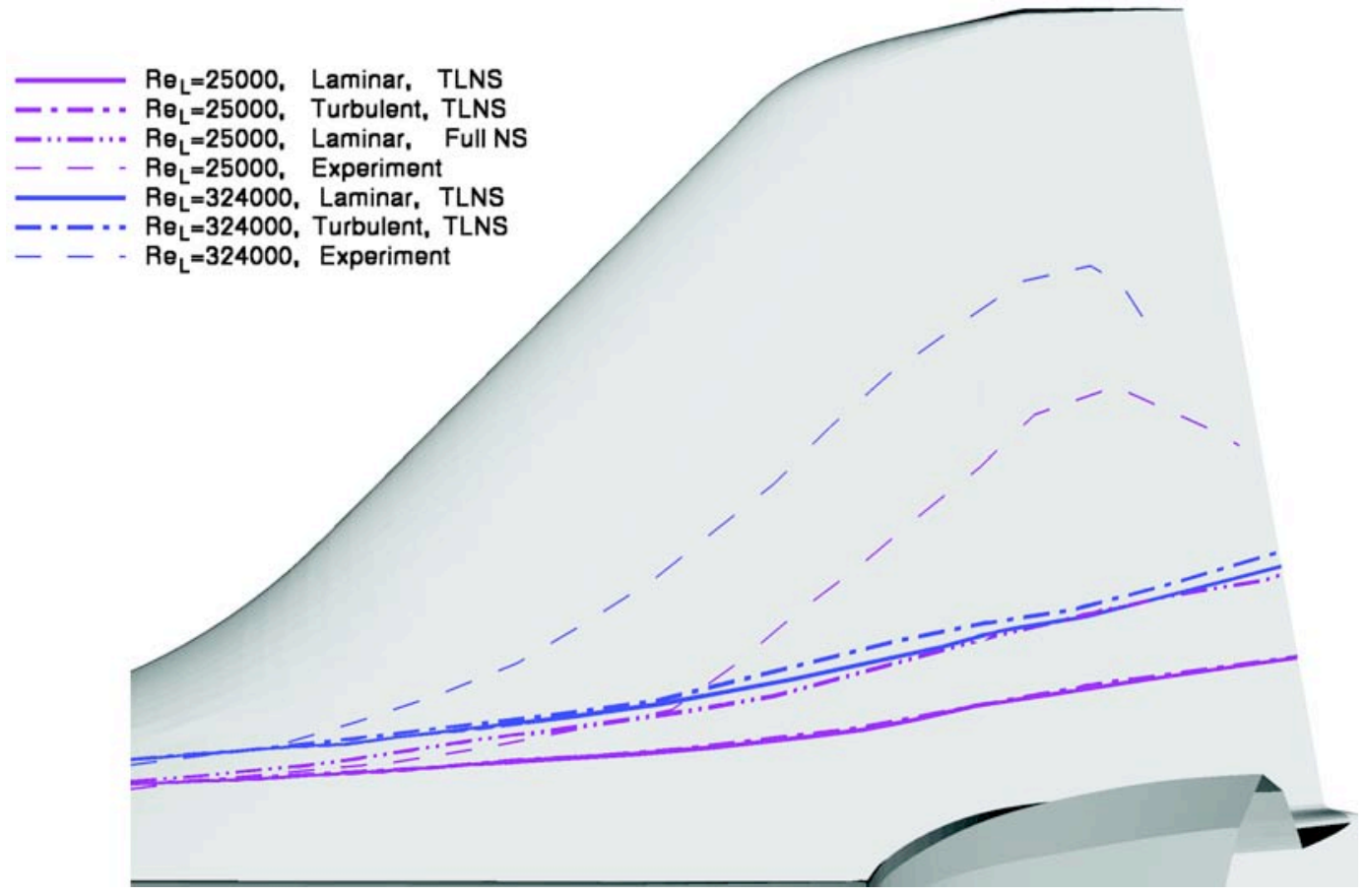

Figure 12. Computed (LAURA) wing leeside separation lines for 0.0075 scale orbiter in hypersonic $\mathrm{CF}_{4}$ at $40^{\circ}$ angle of attack for various freestream Reynolds numbers and flow solutions. 


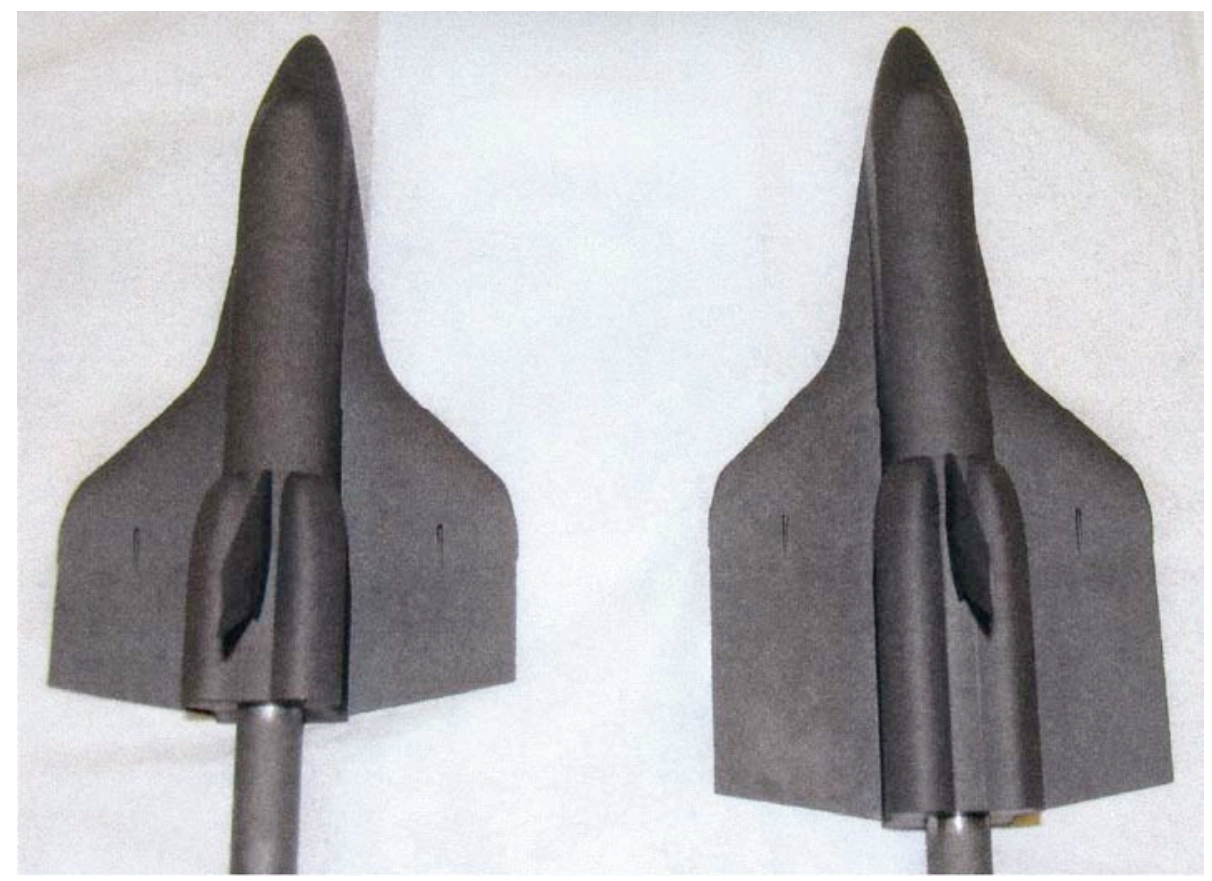

Figure 13. Extended 0.004 scale orbiter test models with +1 and +2 inch extensions.

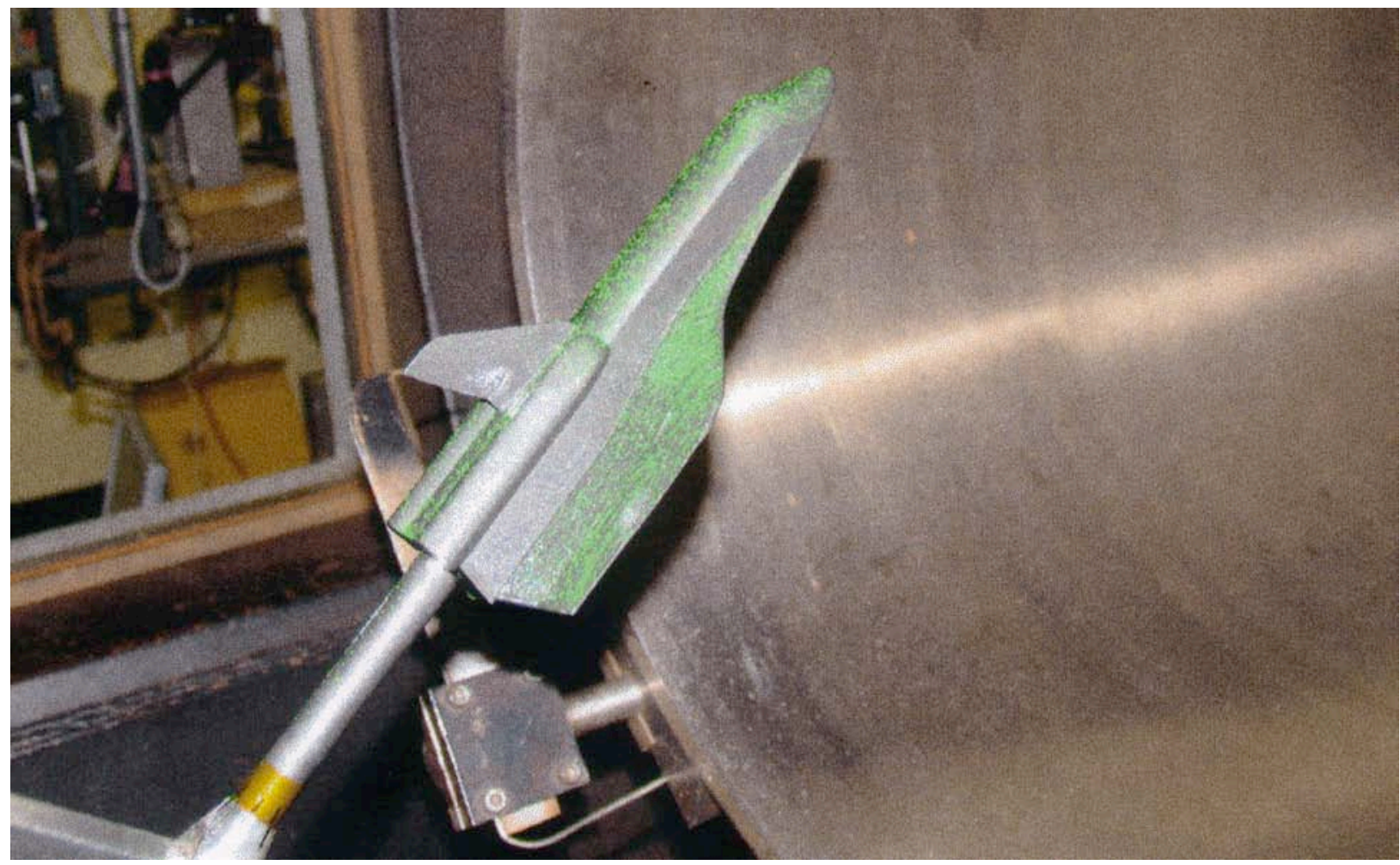

Figure 14. Post-run set-up image of +2 orbiter model in hypersonic $\mathrm{CF}_{4}$ wind tunnel with residue from fluorescent powder coating. 


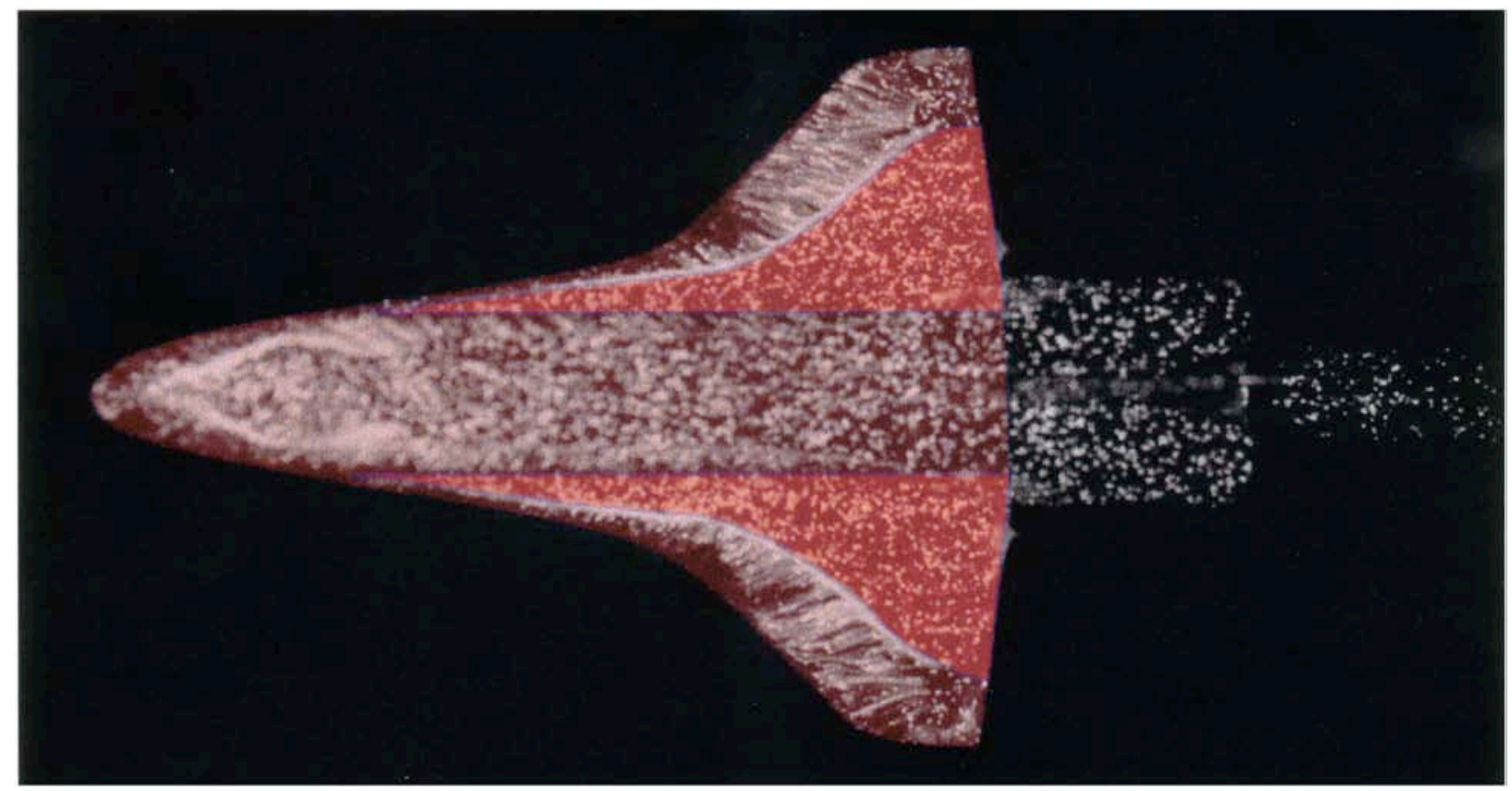

(a)

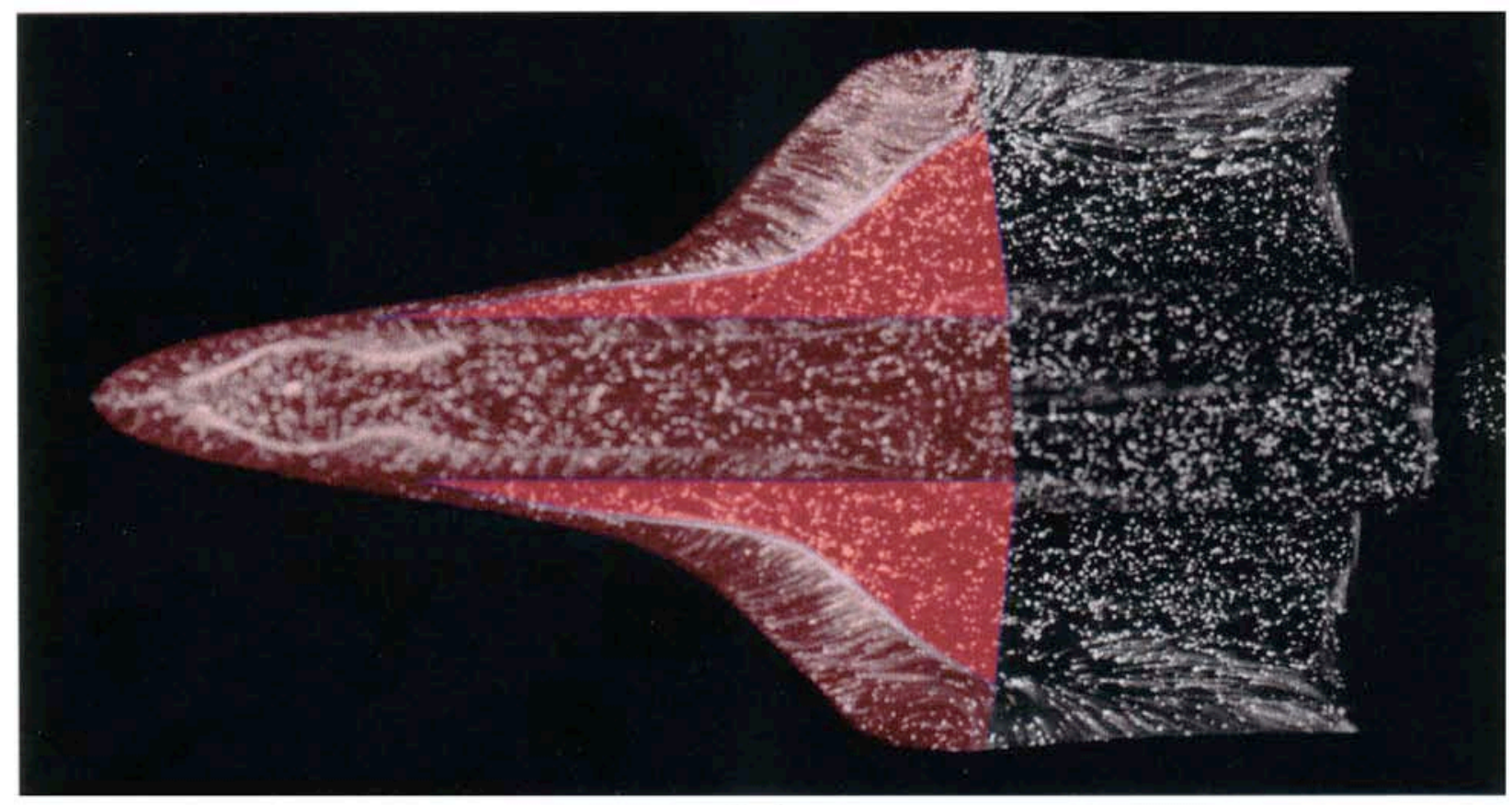

(b)

Figure 15. Separation lines from in-situ fluorescent oil flow on 0.004 scale orbiter in the hypersonic $\mathrm{CF}_{4}$ wind tunnel at $\operatorname{Re}_{\mathrm{L}}=151,000$ for $(a)+0$ inch extended and (b) +2 inch extended models. 


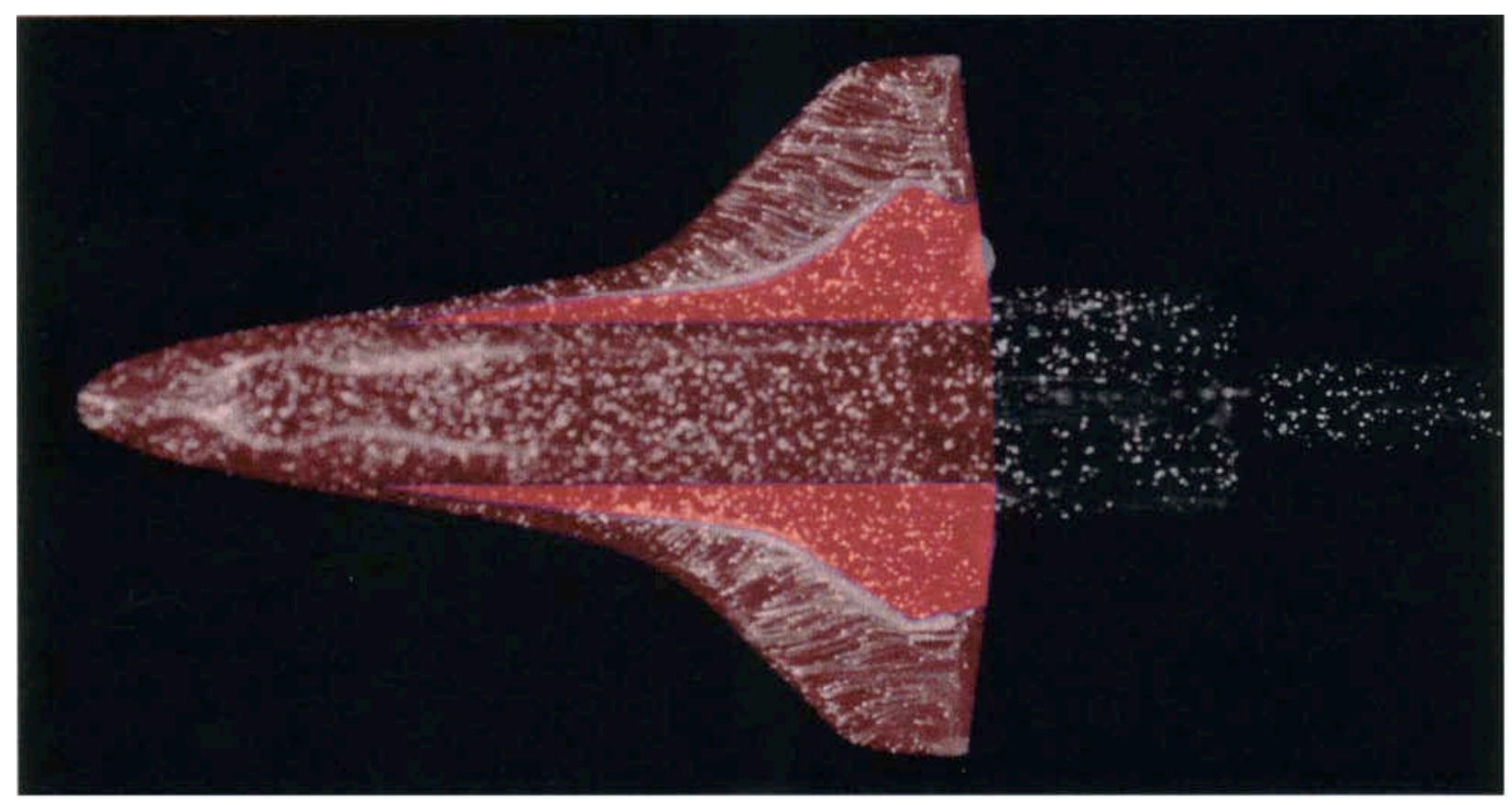

\section{(a)}

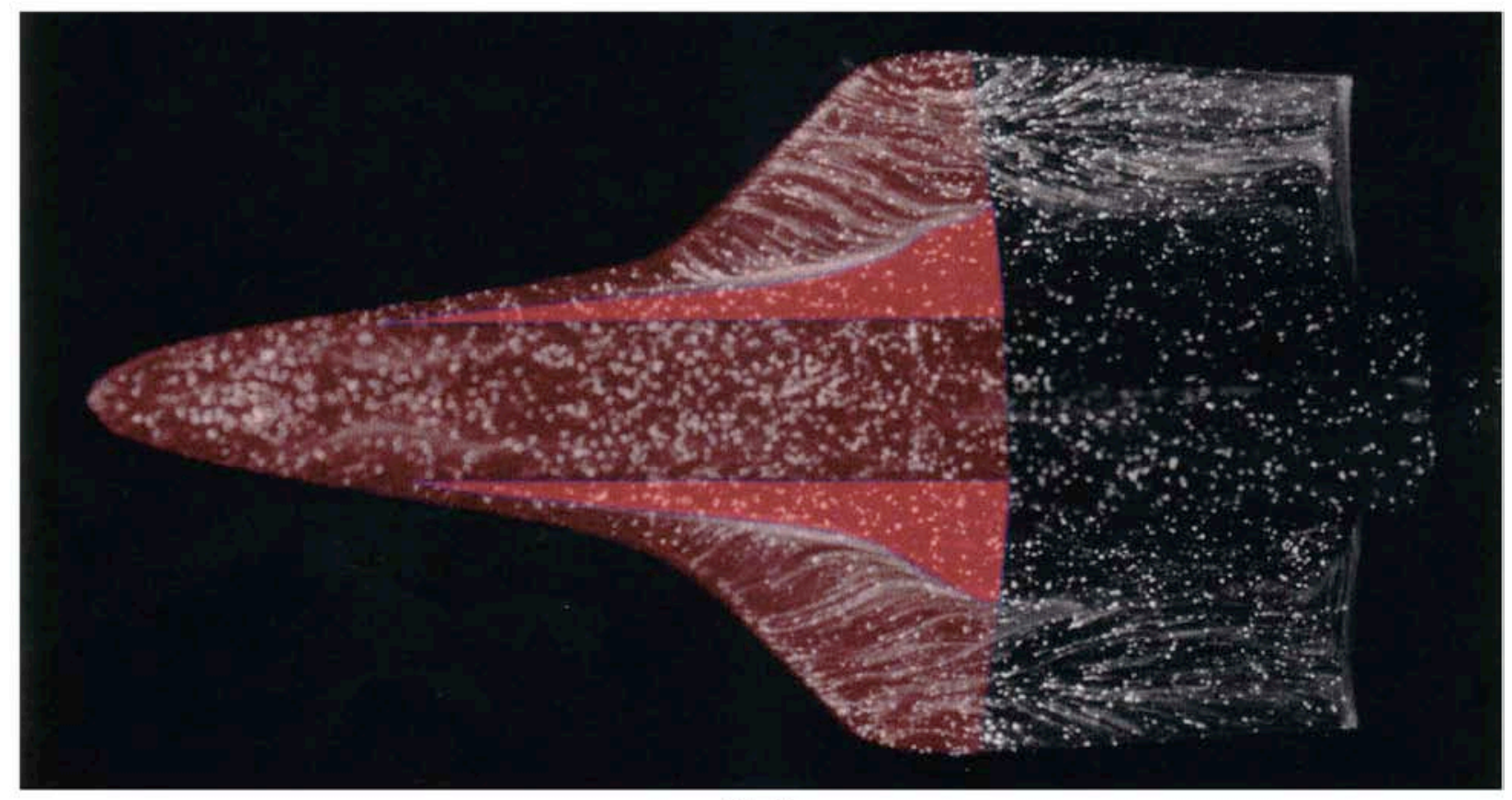

(b)

Figure 16. Separation lines from in-situ fluorescent oil flow on $\mathbf{0 . 0 0 4}$ scale orbiter in the hypersonic $\mathbf{C F}_{4}$ wind tunnel at $\mathrm{Re}_{\mathrm{L}}=41,000$ for (a) +0 inch extended and (b) +2 inch extended models. 

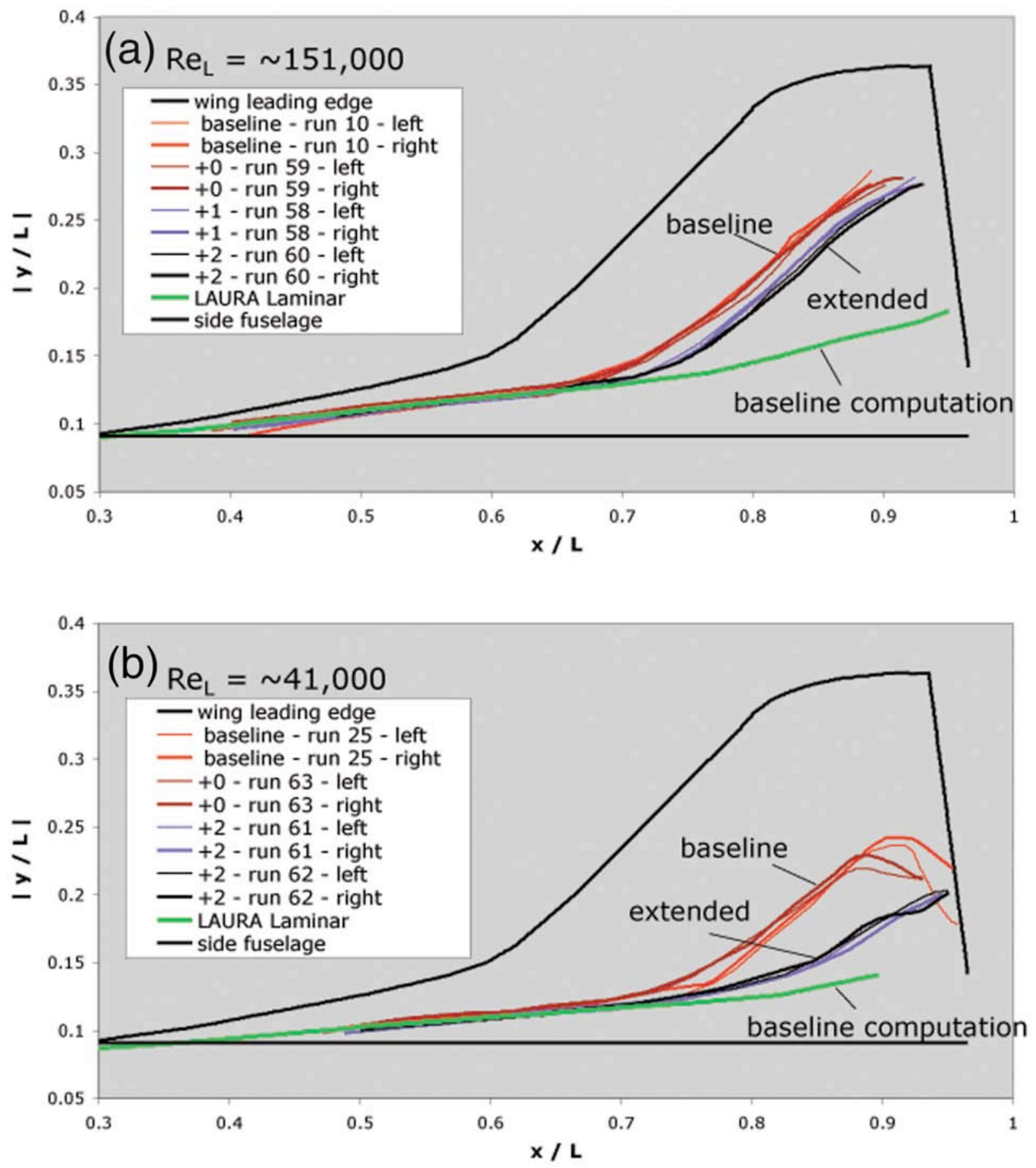

Figure 17. Comparisons of wing leeside separation lines using computed baseline and experimental baseline and extended models for hypersonic $\mathrm{CF}_{4}$ for (a) $\mathrm{Re}_{\mathrm{L}}=\sim 151,000$ and (b) $\mathrm{Re}_{\mathrm{L}}=\sim 41,000$. 


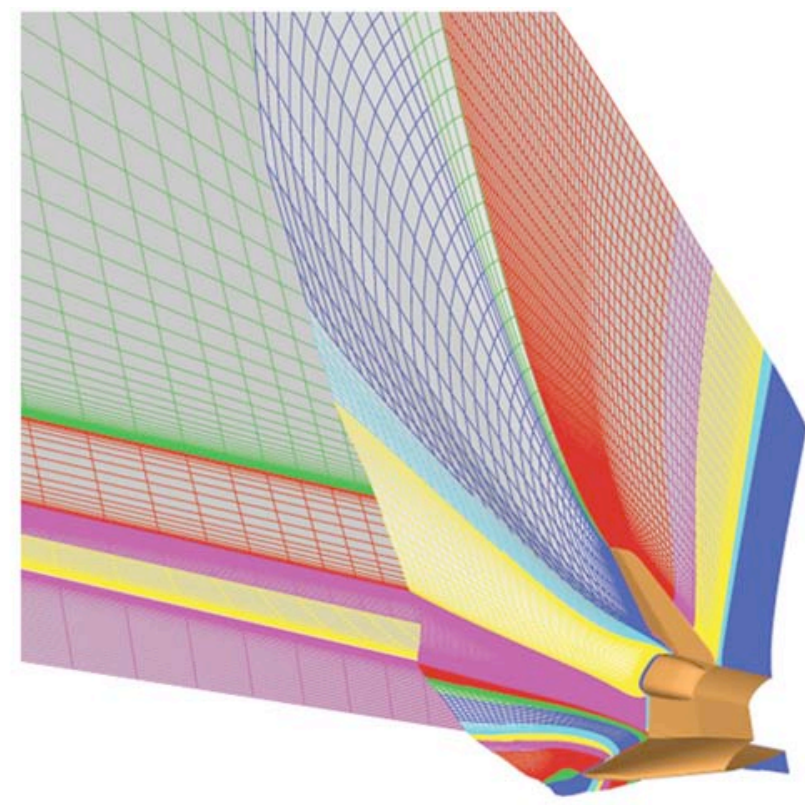

Figure 18. Detail of volume grid for extended wakeflow region.

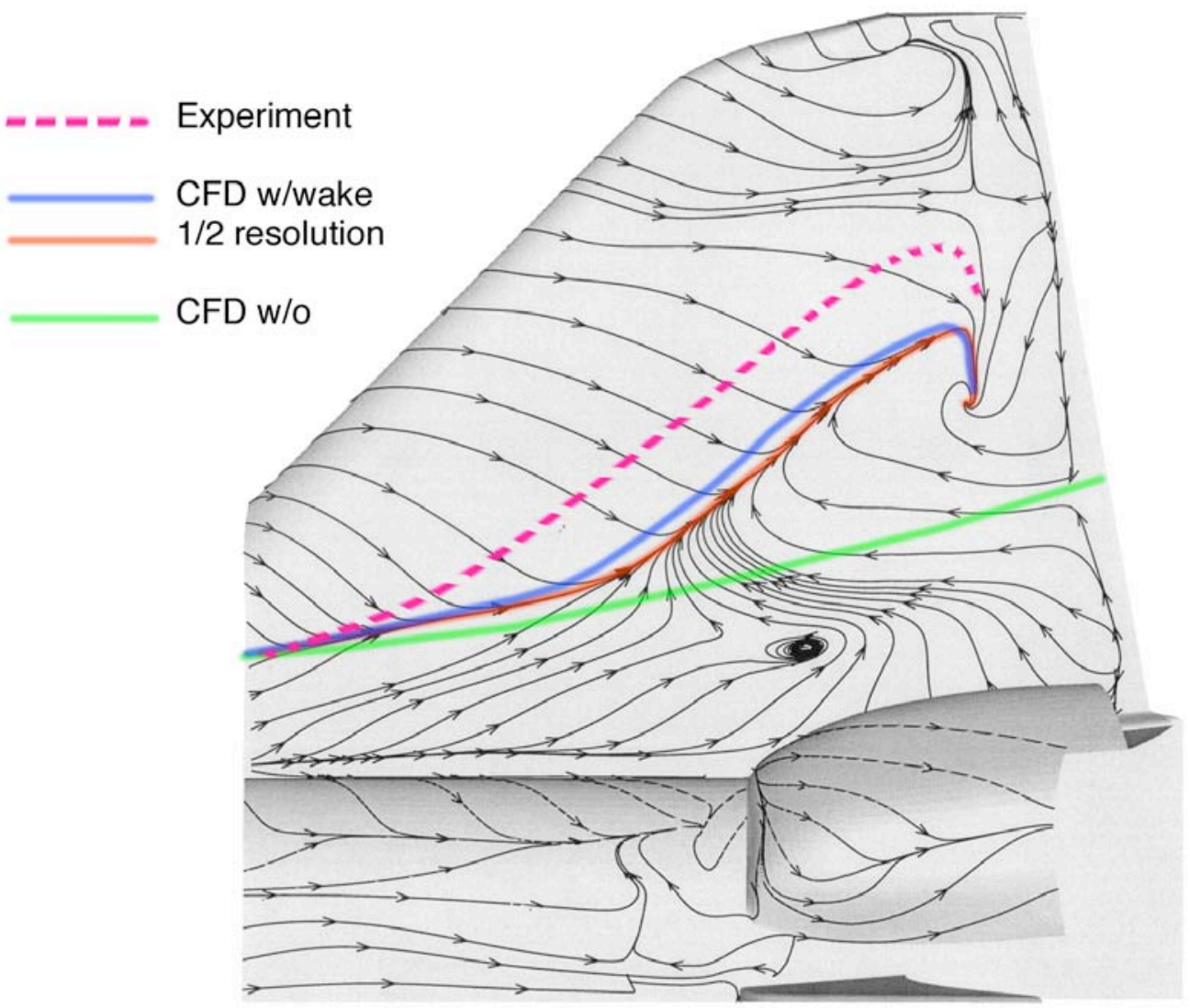

Figure 19. Computed wing leeside surface streamlines with extended wake flow region for 0.004 scale orbiter in hypersonic $\mathrm{CF}_{4}$ at $40^{\circ}$ angle of attack for $\mathrm{Re}_{\mathrm{L}}=324,000$. 


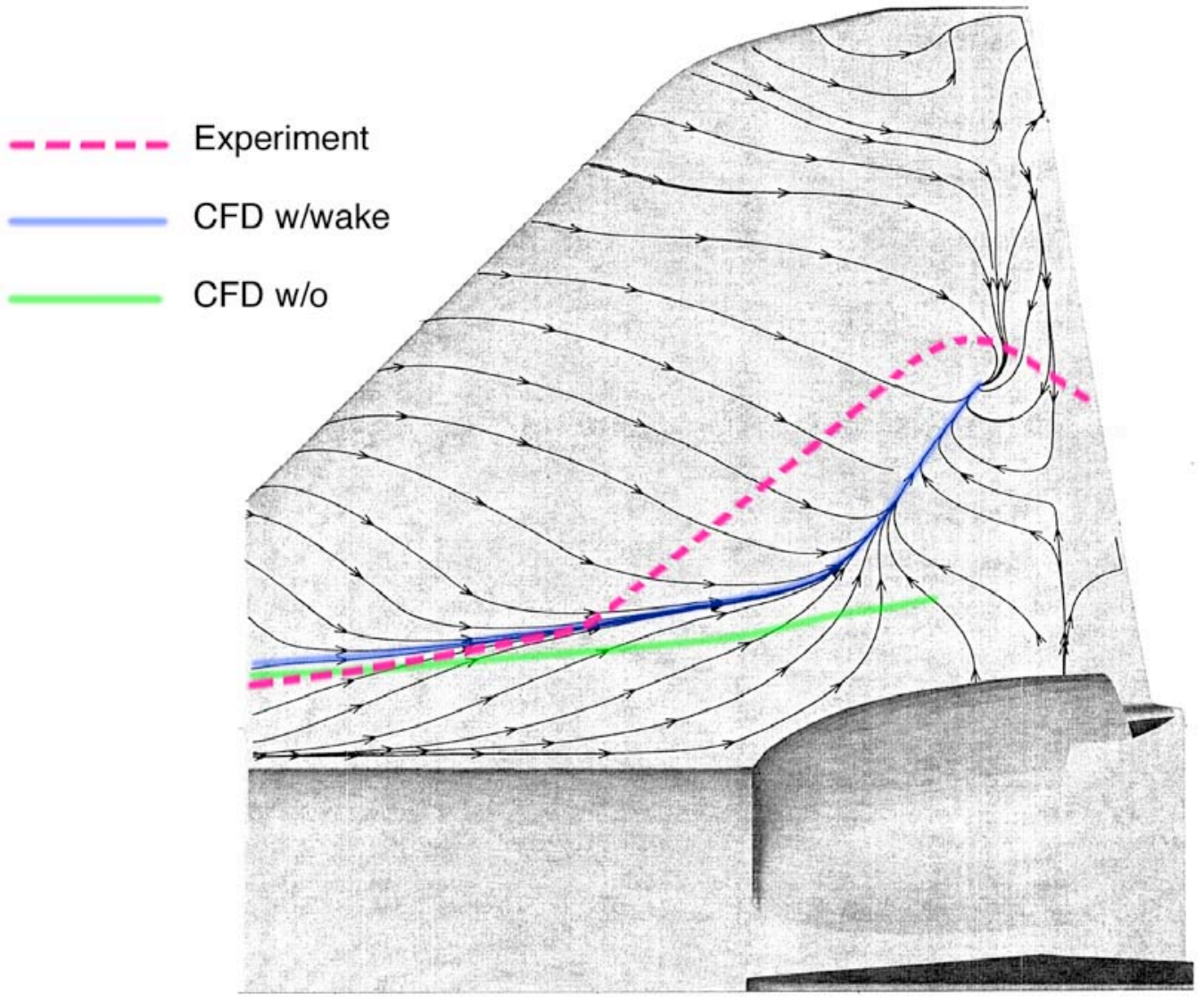

Figure 20. Computed wing leeside surface streamlines with extended wake flow region for

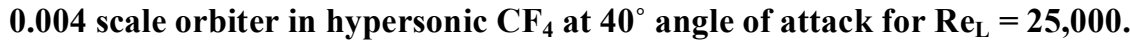

